\title{
Pavlovian appetitive discriminative conditioning in Aplysia californica
}

\author{
RUTH M. COLWILL, KEVIN GOODRUM, and ANDRE MARTIN \\ Brown University, Providence, Rhode Island
}

\begin{abstract}
Three experiments demonstrated Pavlovian appetitive discrimination learning in the marine mollusc, Aplysia californica. In each experiment, subjects were exposed to two conditioned stimuli; one stimulus (CS+) was paired with food presentations and the other stimulus (CS-) was never followed by food. In Experiments 1 and 3 different chemosensory stimuli were used, and in Experiment 2 different tactile stimuli were used. For both types of conditioned stimuli, bite responses occurred significantly more often to the CS+ than to the CS- Experiment 2 also showed that Aplysia could learn a reversal of this discrimination. Experiment 3 showed that nonreinforced presentations of CS+ resulted in a decline in the frequency of conditioned biting. The implications of these results for neurobiological analyses of learning are discussed.
\end{abstract}

In a typical Pavlovian discriminative conditioning procedure, subjects are exposed to two conditioned stimuli (CSs) that differ in their temporal relation to an unconditioned stimulus (US). One of these stimuli (CS+) immediately precedes presentations of the US; the other stimulus (CS-) is never paired with that US. Differential responding to the $\mathrm{CS}+$ and $\mathrm{CS}-$ is found to emerge over the course of discrimination training in various vertebrate (e.g., Hammond, 1967; Hoffman \& Fitzgerald, 1982; Moore, 1972; Pavlov, 1927; Rescorla, 1980; Schneiderman, 1972) and invertebrate subjects (e.g., Bitterman, Menzel, Fietz, \& Schafer, 1983; Block \& McConnell, 1967; Fukushi, 1979; Nelson, 1971; Ricker, Brzorad, \& Hirsch, 1986).

Of particular interest are reports of Pavlovian discriminative conditioning in those invertebrates especially suited to a neurophysiological analysis of plasticity. Behavioral sensitivity to the differential treatments of a CS+ and CS - has been found in several experiments using aversive USs with the marine mollusc Aplysia californica (Carew, Hawkins, \& Kandel, 1983), the leech Haemopis marmorata (Karrer \& Sahley, 1988), and the terrestrial mollusc Limax maximus (Sahley, Gelperin, \& Rudy, 1981). For example, in the leech, Karrer and Sahley (1988) paired one food (e.g., raw chicken) but not

This research was supported by National Science Foundation Grant BNS-8922551 to R.M.C. and by funds from the Howard Hughes Medical Institute. K.G. and A.M. were supported by research fellowships awarded by Brown University's Early Identification Program. We thank Robin Absher and Emily Whitcomb for assistance with data collection. Experiment 1 was presented at the 65th Annual Meeting of the Eastern Psychological Association in Providence and at the Second Annual Summer Research Symposium at Brown University in August 1993. A brief description of Experiment 1 also appears in Colwill (1996). Reprint requests should be addressed to R. M. Colwill, Department of Psychology, Brown University, Box 1853, Providence, RI 02912 (e-mail: ruth_colwill@brown.edu). another food (e.g., raw liver) with a quinidine sulfate solution. On test trials, subjects were given a choice between raw beef and either the CS+ or the CS - foods. The preference for the $\mathrm{CS}+$ relative to raw beef declined markedly over the course of conditioning, whereas there was no change in the preference for the CS-. Using Aplysia californica, Carew et al. (1983) paired an aversive tail-shock US with one tactile CS (e.g., mantle stimulation) but not another tactile stimulus (e.g., siphon stimulation). On test trials, the duration of siphon withdrawal was substantially longer to the CS+ than to the $\mathrm{CS}-$. These results indicate that invertebrates can be sensitive to differences in the temporal arrangements of CSs and USs.

The purpose of the present experiments was to explore further aspects of Pavlovian conditioning in Aplysia californica. Previous work with this invertebrate has focused on aversive conditioning procedures (Carew et al., 1983; Carew, Walters, \& Kandel, 1981; Colwill, Absher, \& Roberts, 1988; Walters, Carew, \& Kandel, 1979, 1981). Our goal has been to complement that work by developing a Pavlovian appetitive conditioning procedure. Such a procedure would provide additional opportunities for comparisons of invertebrate and vertebrate learning. Furthermore, it would allow a within-species assessment of the generality of the behavioral principles and neural mechanisms derived from studies of aversive conditioning. In three experiments, learning about an appetitive food US was assessed using a Pavlovian discriminative conditioning procedure. Chemosensory stimuli served as CS+ and CS - in Experiments 1 and 3; tactile stimuli served as CS+ and CS - in Experiment 2. All three experiments yielded evidence of differential responding to the $\mathrm{CS}+$ and $\mathrm{CS}-$. In addition, Experiment 2 showed that subjects could learn a reversal of the Pavlovian discrimination and Experiment 3 showed that responding to $\mathrm{CS}+$ extinguished when presentations of the food US were discontinued. 


\section{EXPERIMENT 1}

In Experiment 1, a Pavlovian discriminative conditioning procedure was used to assess the ability of Aplysia to detect which one of two chemosensory CSs (lemon seawater and banana seawater) was paired with a food US. On CS + trials, one of the flavor CSs was applied to the lips for $10 \mathrm{sec}$ and then immediately substituted for a small piece of dried seaweed; on CS - trials, the other flavor CS was applied to the lips for $10 \mathrm{sec}$ and withdrawn without a food presentation. Following a series of acquisition trials, an extinction test was conducted by an experimenter blind to the specific conditioning histories of the subjects. In this test, there were two presentations each of the CS+ and the CS - but no foods were given. The question of interest was whether the differential treatment of the CS+ and the CS - would lead to the establishment of differential control over appetitive behavior by those stimuli.

The complete repertoire of feeding behaviors in Aplysia has been described in detail elsewhere (e.g., Kandel, 1979; Kupfermann, 1974; Leonard \& Lukowiak, 1986). We selected one aspect of the feeding sequence, biting, for observation during the $\mathrm{CS}$ presentations. Biting refers to an elaborate sequence initiated by the opening, closing, and reopening of the lips with protraction of the odontophore. The mouth then opens and the two halves of the radula separate and then close again. Finally, the odontophore begins to retract and rotate backwards, and the mouth closes. In our experiments, we recorded a bite response whenever the mouth opened to reveal the radula, an easily visible white structure. It was anticipated that pairings of the CS+ and food would lead to an increase in the frequency of bite responses to the CS+. This prediction was based on the numerous vertebrate demonstrations of the conditioning of consummatory responses (e.g., Brown \& Jenkins, 1968; Gormezano, 1966, 1972; Jenkins \& Moore, 1973; Pavlov, 1927, 1928).

\section{Method}

\section{Subjects}

The subjects were 16 Aplysia californica purchased from the Aplysia Resource Facility at the University of Miami. On arrival at the laboratory, the subjects were housed in groups of 5 or 6 within a 200-gal tank containing filtered and aerated artificial seawater (Instant Ocean) kept between $12^{\circ}$ and $14^{\circ} \mathrm{C}$. The subjects were maintained on a diet of red gracilaria for 2 weeks. At the end of the 2nd week, the subjects were rehoused in individual perforated pans $(25 \times 14 \times 10.5 \mathrm{~cm})$ that floated freely in the same tank. At this time, the subjects were shifted to a diet of dried laver. This allowed superior control over the amount and time of food ingestion in the home tank. The subjects were fed pieces of dried laver approximately $2 \mathrm{~cm}$ square on alternate days throughout the duration of the experiment. They weighed approximately $100 \mathrm{~g}$ at the start of the experiment.

\section{Materials}

All experimental procedures were conducted in eight identical white plastic containers measuring approximately $17.5 \times 10 \times$ $12 \mathrm{~cm}$. These conditioning pans were filled with artificial seawater from the home tank. The subjects were run in squads of 8 . At the end of each session, the seawater in the conditioning pans was discarded. Seawater in the home tank was replaced at the end of each day to maintain a constant volume. The lemon-seawater CS was a mixture of 1 part Pure Lemon Extract (McCormick \& Co., Inc.) and 19 parts artificial seawater; the banana-seawater CS was a mixture of 1 part Imitation Banana Extract (McCormick \& Co., Inc.) and 19 parts artificial seawater. Fresh mixtures were made daily. The CSs were administered in plastic 1-cc syringes. Dried seaweed (laver) cut into small pieces approximately $1 \mathrm{~cm}$ square served as the US.

\section{Procedure}

US pretraining. This training was designed to ensure that food USs were eaten promptly during the conditioning sessions. All subjects received four presentations of the food US spaced at least 2 min apart. On a trial, a piece of laver held in forceps was gently wiped across the lips of each subject. The trial terminated when, following opening of the mouth, the two radular halves were extended and the piece of laver was grasped and swallowed.

Discriminative Pavlovian conditioning. Each session contained six CS+ and six CS - trials with a minimum intertrial interval (ITI) of $60 \mathrm{sec}$. On CS+ trials, a plastic syringe holding $.5 \mathrm{cc}$ of flavored seawater was touched to the lips of a subject and kept in contact with the lips for $10 \mathrm{sec}$. A drop of the flavored seawater was squeezed onto the lips during the last $5 \mathrm{sec}$ of the CS presentation. A food US held in forceps was touched to the lips coincident with the removal of the CS+. If the food US was not grasped immediately, it was wiped across the subject's lips until it was ingested or until the subject withdrew from the food. On the latter occasions, the food US was discarded. On CS - trials, an identical plastic syringe holding $.5 \mathrm{cc}$ of the other flavored seawater was touched to the lips of a subject and kept in contact with the lips for $10 \mathrm{sec}$. A drop of the flavored seawater was squeezed onto the lips during the second 5-sec period of the CS presentation. CS - trials terminated with the removal of the CS and without the administration of a food US. The order of $\mathrm{CS}+$ and $\mathrm{CS}-$ trials was randomized, with the constraint that there be no runs of more than three same-type trials. Trial sequences varied across sessions. There were 14 sessions of this discrimination training. On the day of testing, the subjects received half a session of discriminative Pavlovian conditioning about $1 \mathrm{~h}$ prior to the test session.

For half of the animals, lemon seawater (L) served as the CS+ and banana seawater $(\mathrm{B})$ as the $\mathrm{CS}-$; for the remaining animals, $\mathrm{B}$ served as the $\mathrm{CS}+$ and $\mathrm{L}$ as the $\mathrm{CS}-$.

Testing. The test session contained two nonreinforced presentations each of the lemon and banana CSs. CS presentations were the same as those in discrimination training except that they lasted for $15 \mathrm{sec}$ and a second drop of the flavored seawater was squeezed onto the lips during the final $5 \mathrm{sec}$. The order of CS presentations was LBBL for half of the subjects trained with $\mathrm{L}$ as CS+ and for half of those trained with $\mathrm{B}$ as $\mathrm{CS}+$; for the remaining subjects, the order of CS presentations was BLLB. During testing, the experimenter administering the CSs and making the behavioral observations was blind to the specific conditioning histories of the subjects.

Behavioral observations. In the discriminative conditioning phase, a subject's behavior on each trial was assigned to one of three categories: bite, lip contact, and withdrawal. A bite was recorded if the subject opened its mouth to reveal the radula at any point during the CS presentation; a lip contact was recorded if the subject either passively or actively maintained lip and/or mouth contact with the plastic syringe throughout the CS presentation; a withdrawal was recorded if the subject turned its head away from the syringe at any point during the CS presentation. These three behavioral categories were also used to judge each subject's behavior during the test trials. However, observations were recorded at 5-sec intervals during the CS and for the 5-sec period immediately following termination of the CS. Observations were confirmed by a second ob- 
server who recorded the data. The second observer was also blind to the specific conditioning histories of the subjects during extinction testing.

\section{Results and Discussion}

\section{US Pretraining}

By the final food presentation, every subject was grasping the food as soon as the food was brought into contact with its lips and mouth.

\section{Discriminative Pavlovian Conditioning}

The percentage of trials with a bite response initially increased to both CS + and $\mathrm{CS}-$. With continued training, however, responding decreased to $\mathrm{CS}-$ and remained high to CSt. This difference between response rates to $\mathrm{CS}+$ and $\mathrm{CS}-$ was obtained in the half session of discrimination training that preceded the extinction test. The mean percentage of CS+ and CS - trials with a bite was 93.8 and 72.9, respectively. All subjects reliably consumed the majority $(>90 \%)$ of the food USs on CS + trials. During the final half session of discrimination training, all food USs were eaten.

\section{Testing}

The most important data from the test session with nonreinforced presentations of the CS + and the CS - are shown in Figure 1. The pair of bars on the left show the percentage of bite responses for lemon $\mathrm{CS}^{+}$and banana CS-; the pair of bars on the right show the percentage of bite responses for banana $\mathrm{CS}+$ and lemon $\mathrm{CS}-$. An overall analysis revealed that the mean percentage of observations recorded as bites was significantly higher to $\mathrm{CS}+$ than to CS $-[$ Wilcoxon $T(13)=7.5, p<.05$ ]. There was a slightly higher likelihood of biting in the period immediately following removal of the CS+ $(56.3 \%)$ than

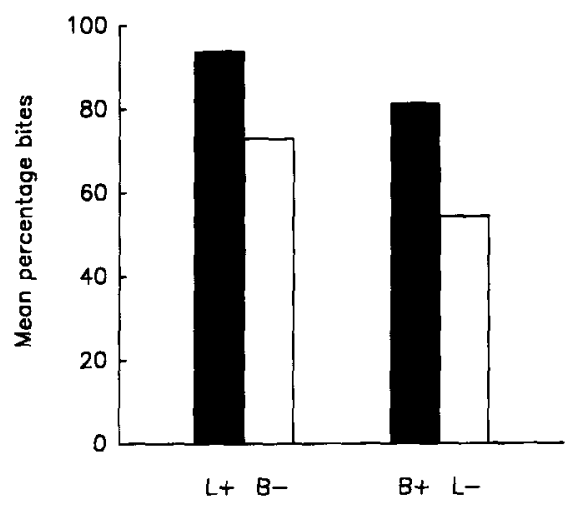

Figure 1. Experiment 1: Results of the discriminative appetitive conditioning experiment with Aplysia in which one chemosensory cue was paired with food (CS+) and a different chemosensory cue was not paired with food (CS-). The percentage of observations recorded as bites are plotted separately for the condition in which lemon served as $\mathrm{CS}+$ and banana as $\mathrm{CS}-(\mathrm{L}+$ and $B-$, respectively) and for the condition in which banana served as $\mathrm{CS}+$ and lemon as $\mathrm{CS}-(\mathrm{B}+$ and $\mathrm{L}-$, respectively). following removal of the CS- $(43.8 \%)$, but this difference was not statistically significant.

The percentage of withdrawal responses was slightly, but not significantly, higher to the CS- $(10.4 \%)$ than to the $\mathrm{CS}+(2.1 \%)$. This finding is generally consistent with the vertebrate literature in which direct measures of behavior to a CS - are difficult to obtain, although some success has been achieved in documenting that pigeons withdraw from nonreinforced discrete visual stimuli (Gaffan \& Hart, 1981; Hearst \& Franklin, 1977; Wasserman, Franklin, \& Hearst, 1974). At least two factors may account for the relatively low incidence of withdrawal responses to the CS - in Experiment 1. One possibility is that the tactile feature common to the administration of the two chemosensory stimuli increased generalization between them. Evidence from the vertebrate literature suggests that such incidental stimuli may retard discrimination learning (Pearce \& Redhead, 1993; see also Mackintosh, 1983). The other possibility is that a subject's efforts to withdraw from the CS- in Experiment 1 were rendered futile because the experimenter maneuvered the CS so that it remained in contact with the animal's lips. Although this contingency guaranteed equivalent exposure to CS+ and CS - in our experiment, it eliminated potential sources of reinforcement that may have otherwise supported a withdrawal response.

Experiment 1 demonstrated Pavlovian conditioning of an appetitive reflex in Aplysia californica. Conditioned biting was preferentially established to a CS paired with a food US relative to an unpaired CS. More importantly, this difference was evident in an extinction test conducted by an experimenter who had no knowledge of the specific conditioning histories of the subjects. This appetitive conditioning procedure is especially attractive for studying learning because the conditioned response can be easily quantified. For example, there was perfect agreement among different observers on whether or not the mouth opened to reveal the radula. In summary, the results of Experiment 1 clearly indicate a sensitivity to the temporal arrangement of a chemosensory CS and a food US in Aplysia californica.

\section{EXPERIMENT 2}

In Experiment 2, we examined whether tactile stimuli could acquire differential control over Aplysia's bite response. Two CSs were fabricated with different textured surfaces that could be applied to the mouth and lips; one of these CSs was paired with a food US and the other was not paired with that US. After a series of acquisition trials, the roles of $\mathrm{CS}+$ and $\mathrm{CS}$ - were switched; now the former CS+ was treated as a CS - and the former CSwas treated as a CS+. Following acquisition of the reversal of the original discrimination, CS + and $\mathrm{CS}-$ were tested in the absence of food by an experimenter blind to the specific conditioning histories of the subjects. The question of interest was whether Aplysia californica would 
evidence differential biting to the $\mathrm{CS}+$ and $\mathrm{CS}-$ consistent with the effective Pavlovian contingencies.

\section{Method}

\section{Subjects and Materials}

The subjects were 8 Aplysia californica obtained from Sea Life Supply (Sand City, CA). They were housed in individual perforated pans $(20 \times 20 \times 10 \mathrm{~cm})$ that floated freely in a 200 -gal tank of filtered and aerated artificial seawater (Instant Ocean) kept between $15^{\circ}$ and $16^{\circ} \mathrm{C}$. The subjects weighed approximately $125 \mathrm{~g}$ at the start of the study and were maintained on a diet of laver. The subjects were fed in the home tank on alternate days. These feedings occurred approximately $1 \mathrm{~h}$ after training once the experiment had started.

The conditioning containers were similar to those used in Experiment 1 but measured $18.5 \times 13 \times 9.5 \mathrm{~cm}$. For all animals, one (S for smooth) of the CSs was the smooth tip of a 1-cc plastic syringe. The other CS ( $\mathrm{R}$ for rough) was made by wrapping the tip of a 1 -cc plastic syringe in a $1-\mathrm{cm}$-wide strip of coarse sandpaper for half the subjects and by gluing small pieces of aquarium gravel to the tip of a 1-cc plastic syringe for the remaining animals. Both modifications produced a surface that felt rough to human observers when rotated across the surface of their lower lips. Because of water damage to the CS constructed from sandpaper, fresh sandpaper was applied to the plastic syringe every 3-4 sessions. The US was a $1-\mathrm{cm}$-square piece of laver.

\section{Procedure}

US pretraining. This training was designed to ensure that food USs were eaten promptly during the conditioning sessions. All subjects received four presentations of the food US spaced at least $2 \mathrm{~min}$ apart. On each trial, a piece of laver held in forceps was gently wiped across the lips of each subject. The trial terminated when, following retraction of the lips, the radula was extended and the piece of laver was swallowed.

CS preexposure. Subjects were preexposed to the CSs in order to assess the rate of unconditioned bite responses elicited by each CS. Each subject received four presentations of each CS with a minimum ITI of $60 \mathrm{sec}$

Discriminative Pavlovian conditioning. Each session contained four CS+ and four CS - trials with a minimum ITI of $60 \mathrm{sec}$. On $\mathrm{CS}+$ trials, one of the plastic syringes was touched to the lips of a subject and rotated across the lips for 5 sec. A food US held in forceps was touched to the lips coincident with the removal of the CS+. If the food US was not grasped immediately, it was wiped across the subject's lips until it was ingested. On $\mathrm{CS}-$ trials, the other plastic syringe was touched to the lips of a subject and rotated across the lips for $5 \mathrm{sec}$. CS - trials terminated with the removal of the CS and without the administration of a food US. The order of CS + and $\mathrm{CS}$ - trials was randomized with the constraint that there be no runs of more than two same-type trials. Trial sequences varied across sessions. There were 12 complete sessions of this discrimination training.

Reversal training began the following day after subjects had received half a session of discriminative Pavlovian conditioning. Stimulus assignments of $\mathrm{CS}+$ and $\mathrm{CS}-$ were switched for the remaining half of the training session and remained switched for the next 20 discrimination-training sessions.

For half of the subjects, the smooth surface (S) initially served as $\mathrm{CS}+$ and the rough surface (R) served as $\mathrm{CS}-$; for the remaining 4 subjects, $\mathrm{S}$ initially served as $\mathrm{CS}-$ and $\mathrm{R}$ served as $\mathrm{CS}+$. Within each of these two conditions, $R$ was the sandpaper-covered syringe for half of the subjects; for the other subjects, $R$ was the gravelcovered syringe.

Testing. Two test sessions were given. Each session contained four nonreinforced $\mathrm{CS}+$ and $\mathrm{CS}-$ presentations with a minimum ITI of $60 \mathrm{sec}$. CS presentations were the same as in discrimination training, but no food was given following CS+. In the first test session, the order of CS presentations was RSSRSRRS for half of the subjects trained with $R$ as CS+ and for half of the subjects trained with S as CS+; for the remaining subjects, the order of CS presentations was SRRSRSSR. These orders were reversed in the second test session. The experimenter administering the CSs and making the behavioral observations during testing was blind to the specific conditioning histories of the subjects.

Behavioral observations. On each trial throughout conditioning and testing, a subject's behavior was scored as a bite if its mouth opened to reveal the radula at any point during the CS presentation. On CS+ trials, the experimenter also noted whether the food US was eaten.

\section{Results and Discussion}

\section{US Pretraining}

By the final food presentation, every subject was grasping the food as soon as the food was brought into contact with its lips and mouth.

\section{CS Preexposure}

During preexposure, at least one bite to one of the CSs was recorded for 6 subjects. The mean rates of responding in this session are shown to the far left of Figure 2. There was no significant difference between $\mathrm{CS}+$ and $\mathrm{CS}-$.

\section{Discriminative Pavlovian Conditioning}

Acquisition and reversal of the discrimination between $\mathrm{CS}+$ and $\mathrm{CS}-$ is plotted in Figure 2. The percentage of trials with a bite response is shown separately for CS+ and CS - trials. Bite responses initially increased to both $\mathrm{CS}+$ and $\mathrm{CS}-$; with continued training, responding remained high to $\mathrm{CS}+$ but decreased to $\mathrm{CS}-$. Following re-

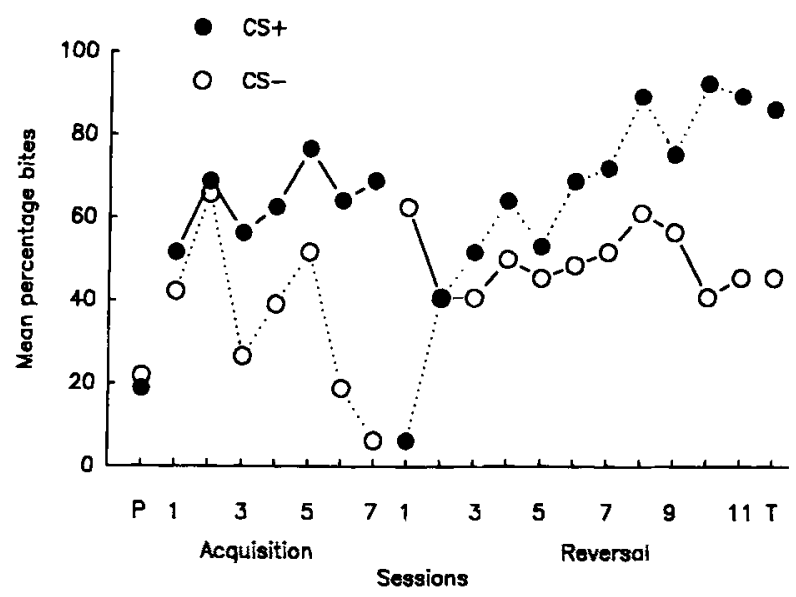

Figure 2. Experiment 2: Acquisition and reversal of a Pavlovian discrimination in which one tactile cue $(\mathrm{CS}+)$ was paired with food and a different tactile stimulus (CS - ) was not paired with food. The percentage of observations scored as bites is shown separately for $\mathrm{CS}+$ and $\mathrm{CS}-$ in each phase of the experiment: $\mathrm{CS}$ preexposure (P), acquisition, reversal, and nonreinforced test $(T)$. Acquisition and reversal data are plotted in blocks of two sessions, except for the final data point of acquisition and the first data point of reversal training. Each of these two points represents half a session. 
versal of the CS+ and CS - contingencies, conditioned biting tracked the shift in the contingencies over time; eventually responding to $\mathrm{CS}+$ (the former $\mathrm{CS}-$ ) exceeded responding to $\mathrm{CS}-$ (the former $\mathrm{CS}+$ ). The final point of acquisition and the first point of reversal training come from the session in which reversal of the $\mathrm{CS}+/ \mathrm{CS}-$ discrimination was begun. Throughout acquisition and reversal of the discrimination, all subjects ate all of the food USs on CS+ trials.

\section{Testing}

The data from the two test sessions with nonreinforced presentations of the $\mathrm{CS}+$ and the $\mathrm{CS}-$ are shown on the far right-hand side of Figure 2. The mean percentage of observations recorded as bites was significantly higher to $\mathrm{CS}+$ than to CS $-[$ Wilcoxon $T(8)=1.5, p<.05]$. On these test trials, all 4 subjects responded more to the rough $\mathrm{CS}+$ than to the smooth $\mathrm{CS}-; 3$ of the 4 subjects responded more to the smooth $\mathrm{CS}+$ than to the rough $\mathrm{CS}-$.

The results of Experiment 2 suggest that Aplysia californica can discriminate between two stimuli on the basis of their textural characteristics. Conditioned biting was evoked significantly more often by the tactile stimulus paired with food than by the tactile stimulus not paired with food. Furthermore, when the CS-US contingencies were reversed, conditioned responding shifted so that by the end of reversal training, there was more responding to the CS+ that had previously served as $\mathrm{CS}$ - than to the $\mathrm{CS}-$ that had previously served as $\mathrm{CS}+$. The ability to acquire discrimination reversals is commonly observed among vertebrates (Gould \& Steinmetz, 1994; Mackintosh, 1974). Although the behavioral observations during initial acquisition and reversal of the discrimination were not conducted blind, confidence in the reliability of those observations is afforded by the results of the extinction test carried out by an experimenter blind to the specific conditioning treatments. Under those circumstances, responding to $\mathrm{CS}+$ continued to be significantly higher than responding to $\mathrm{CS}-$.

\section{EXPERIMENT 3}

The main purpose of Experiment 3 was to explore the effect of suspending presentations of the US on responding to $\mathrm{CS}+$ and $\mathrm{CS}-$. Several studies using invertebrates have reported that responding to a $\mathrm{CS}+$ declines when the US is withheld (Bitterman et al., 1983; Block \& McConnell, 1967; Carew et al., 1981; Henderson \& Strong, 1972). In Experiment 3, the effect of an extinction procedure on responding to a $\mathrm{CS}+$ that had been paired with a food US was explored. Subjects were given discriminative conditioning with two chemosensory stimuli, almond and lemon seawater. One of the stimuli (CS+) was paired with food; the other stimulus (CS-) was never reinforced. Extinction sessions were then conducted in which both CS+ and CS - were presented but delivery of the food US was discontinued. Biting to the CSs was recorded during acquisition and extinction of the Pavlovian discrimination. During extinction, experimental procedures and behavioral observations were carried out by an experimenter blind to the specific conditioning histories of the subjects.

\section{Method}

\section{Subjects and Materials}

The subjects were 8 Aplysia californica purchased from Sea Life Supply (Sand City, CA). They were housed and maintained as in Experiment 2.

Experimental sessions were conducted in the conditioning containers used in Experiment 2 . The CSs were chemosensory cues administered in plastic 1-cc syringes. One of the CSs (A, for almond) was 1 part almond extract mixed with 49 parts seawater; the other CS ( $\mathrm{L}$, for lemon) was 1 part Durkee-brand lemon extract mixed with 24 parts seawater. These values were based on pilot work that was conducted to determine a concentration of the almond mixture that did not produce a strong withdrawal response. The US was 1 -cm-square pieces of laver.

\section{Procedure}

US pretraining. This training was designed to ensure that food USs were eaten promptly during the conditioning sessions. All subjects received two sessions of US pretraining. In each session, six presentations of the food US spaced at least 2 min apart were given to each subject. On each trial, a piece of food held in forceps was gently wiped across the lips of each subject. The trial terminated when, following opening of the mouth, the radula was extended and the piece of food was grasped and swallowed.

Discriminative Pavlovian conditioning. Each session contained $10 \mathrm{CS}+$ and $10 \mathrm{CS}-$ trials with a minimum ITI of $60 \mathrm{sec}$. On $\mathrm{CS}+$ trials, one of the plastic syringes was touched to the lips of a subject for $5 \mathrm{sec}$. A food US held in forceps was touched to the lips coincident with the removal of the CS + . If the food US was not grasped immediately, it was wiped across the subject's lips until it was ingested or until the subject withdrew from the food. On the latter occasions, the food US was discarded. On CS - trials, the other plastic syringe was touched to the lips of a subject for $5 \mathrm{sec}$. CStrials terminated with the removal of the CS and without the administration of a food US. For half of the animals, A served as CS+ and $L$ as $C S-$; for the remaining animals, $L$ served as $C S+$ and $A$ as $\mathrm{CS}-$. The order of CS+ and CS - trials was randomized with the constraint that there be no runs of more than four same-type trials. Trial sequences varied across sessions. There were 12 sessions of this discrimination training. On the day that extinction began, the subjects first received a session of discrimination training containing six CS+ and CS - trials. At the end of this session, the subjects were renumbered to conceal their identities from the experimenter conducting the extinction trials.

Extinction. There were three sessions of extinction, each containing six nonreinforced presentations each of the lemon and almond CSs. CS presentations were the same as in discrimination training. The order of CS presentations was randomized with the constraint that there be no runs of more than two same-type CSs. The experimenter administering the CSs and making the behavioral observations was blind to the specific conditioning histories of the subjects. No food USs were delivered during the extinction sessions.

Behavioral observations. In both the discriminative conditioning and extinction phases, a subject's behavior on each trial was observed. A bite was recorded if at any point during the CS presentation, the subject opened its mouth and revealed the radula. On CS+ trials in the discrimination training phase, the experimenter recorded whether the food USs were eaten. 


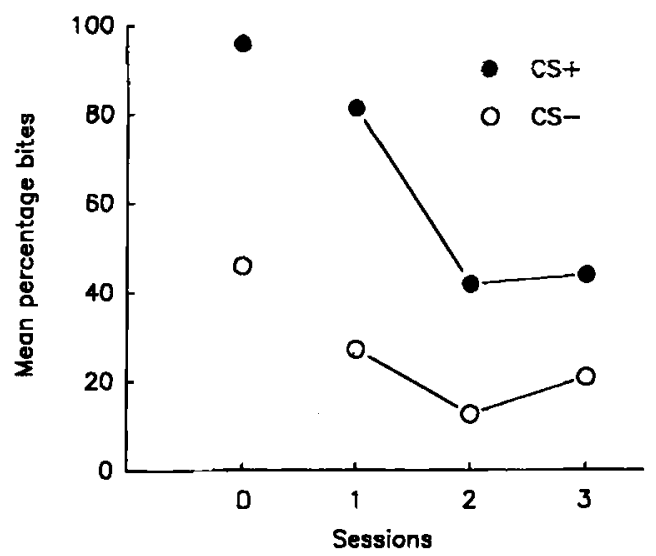

Figure 3. Experiment 3: Extinction of a Pavlovian appetitive discrimination. The mean percentage of bites observed to CS+ (filled circles) and CS - (open circles) is shown for the session of discrimination training (D) prior to extinction and for the three extinction sessions in which both CS+ and CS - were presented without food.

\section{Results and Discussion}

\section{US Pretraining}

By the final food presentation, every subject was grasping the food as soon as the food was brought into contact with its lips and mouth.

\section{Discriminative Pavlovian Conditioning}

Bite responses increased in frequency on CS+ trials and declined in frequency on CS - trials over the course of discrimination training. In the session of discrimination training immediately prior to the first session of extinction, responding to $\mathrm{CS}+$ exceeded responding to $\mathrm{CS}-$ [Wilcoxon $T(7)=0, p<.05$ ]. The mean percentage of bites to CS+ and $\mathrm{CS}-$ in that session are shown on the left of Figure 3. During this session, every animal consumed all of its food USs on the CS+ trials.

\section{Testing}

On the right of Figure 3 are the results of the three extinction tests. Responding declined to both CS+ and CSalthough a difference between them was preserved across extinction. The mean percentage of bites to $\mathrm{CS}+$ in the final extinction session was significantly lower than that in the final half session of discrimination training [Wilcoxon $T(8)=1, p<.05$ ]. Also, the difference in responding to $\mathrm{CS}+$ in the first and second extinction sessions was significant [Wilcoxon $T(8)=1.5, p<.05]$. Comparisons of the mean percentage of observations recorded as bites to $\mathrm{CS}+$ and $\mathrm{CS}-$ revealed significant differences in all three extinction sessions [Wilcoxon $T \mathrm{~s}(8) \leq 2, p \mathrm{~s}<.05$ ]. Inspection of the combined test data revealed that all 4 animals responded more to $\mathrm{A}+$ than $\mathrm{L}-$, that 3 of the 4 animals responded more to $\mathrm{L}+$ than to $\mathrm{A}-$, and that 1 animal responded equally to $\mathrm{L}+$ and $\mathrm{A}-$.

The results of Experiment 3 confirm that Aplysia californica is sensitive to the temporal arrangement of a CS and a positive US. Conditioned biting was preferentially established to a CS paired with a food US relative to an unpaired CS. Furthermore, when pairings of the CSt and food were discontinued, responding to $\mathrm{CS}+$ decreased. This observation is consistent with other reports that repeated nonreinforced presentations of a $\mathrm{CS}+$ lead to a decline in conditioned responding in vertebrates (Annau \& Kamin, 1961; Gormezano, 1972; Pavlov, 1927; Schneiderman, Fuentes, \& Gormezano, 1962; Smith, 1968; Wagner, Siegel, Thomas, \& Ellison, 1964).

\section{GENERAL DISCUSSION}

In three experiments, the invertebrate Aplysia californica demonstrated an ability to respond differentially to chemosensory cues (Experiments 1 and 3 ) and to tactile cues (Experiment 2) as a function of their temporal relation to a food US. For both types of CSs, Aplysia exhibited more biting to the CS+ than to the CS-. Moreover, in Experiment 2, Aplysia acquired a reversal of the discrimination between $\mathrm{CS}+$ and $\mathrm{CS}-$, and, in Experiment 3 , evidenced extinction of conditioned biting to $\mathrm{CS}+$ when the food USs were discontinued.

These results complement previous reports of Pavlovian conditioning in Aplysia californica in several ways. First, they extend the findings of other studies showing that Aplysia was able to detect and learn about different chemosensory and tactile stimuli (Carew et al., 1983; Carew et al., 1981; Colwill et al., 1988; Walters et al., 1981). Second, they confirm previous reports documenting that Aplysia was sensitive to the temporal arrangements of CSs and USs (Hawkins, Carew, \& Kandel, 1986; Hawkins, Lalevic, Clark, \& Kandel, 1989; Walters, 1989). It is especially impressive that responding was greater to the CS+ than to the CS - in each of the experiments reported here independently of the specific stimulus identities. Research with other invertebrates has not always found conditioning effects to be orthogonal to the particular stimulus assignments (Farley et al., 1990; Mpitsos \& Cohan, 1986). Third, Experiment 3 further establishes that nonreinforced presentations of a previously reinforced stimulus is an effective extinction procedure (Carew et al., 1981; Colwill et al., 1988). Taken together, these data provide strong support for the value of Aplysia as a model system for the study of the neural basis of learning.

What cannot be clearly determined from the present demonstrations, however, is the nature of the process underlying the plasticity observed in a Pavlovian discrimination procedure. In both the vertebrate and invertebrate learning literatures, it has been common to assert that a difference in responding to $\mathrm{CS}+$ and $\mathrm{CS}-$ reflects the acquisition of an association between the $\mathrm{CS}+$ and the US (Mackintosh, 1983; Rescorla, 1967). However, several authors have suggested that the pairing of two events does not have to establish an association between them to produce a modification in behavior (DeCola \& Fanselow, 1995; Farley \& Alkon, 1985; Mitchell, Kirschbaum, \& Perry, 1975; Mitchell, Parker, \& Johnson, 1976; Mitchell, Scott, \& Mitchell, 1977; Pfautz, Donegan, \& Wagner, 1978; Rescorla, 1984; Rescorla \& Holland, 1976). For 
example, an argument may be made that differential responding to CS+ and CS - reflects only the operation of nonassociative factors. According to this view, the US serves to sensitize responses to both the CS+ and the CSbut disproportionately arrests habituation to the $\mathrm{CS}+$ relative to the CS - because of the greater temporal proximity of the CS+ and the US. Colwill (1996) has discussed these accounts of differential behavior in the Pavlovian discrimination paradigm and has described some behavioral techniques for identifying the contribution of associative factors to Pavlovian conditioning (see also Colwill \& Motzkin, 1994; Holland, 1990).

Finally, it is worth noting the potential contribution of these experiments to the study of the neurobiology of plasticity. Considerable progress has been made in tracing the neural circuitry underlying appetitive behavior in Aplysia. Various neurons have been identified that are involved in the process of detecting (e.g., Teyke, Weiss, \& Kupfermann, 1990a, 1990b) and ingesting food (e.g., Cohen, Weiss, \& Kupfermann, 1978; Cropper, Kupfermann, \& Weiss, 1990; Fiore \& Meunier, 1979; JahanPawar \& Fredman, 1983; Rosen, Miller, Weiss, \& Kupfermann, 1988; Weiss, Cohen, \& Kupfermann, 1978). Moreover, Susswein and Byrne (1988) have characterized buccal cells that appear to serve as initiators of patterned activity consistent with that observed in the ingestion and rejection of food. Other work has succeeded in identifying several neuropeptides in the buccal cells (Cropper, Miller, et al., 1990; Cropper, Tenenbaum, Kolks, Kupfermann, \& Weiss, 1987; Lloyd, Frankfurt, Stevens, Kupfermann, \& Weiss, 1987; Lloyd, Mahon, et al., 1985) and in characterizing their modulatory effects on specific buccal neurons (Baux, Fossier, Trudeau, \& Tauc, 1993; Sossin, Kirk, \& Scheller, 1987).

To date, however, there have been relatively few learning procedures using appetitive behavior in Aplysia (Lickey, 1968; Lickey \& Berry, 1966; Susswein \& Schwarz, 1983; Susswein, Schwarz, \& Feldman, 1986). Our experiments describe a Pavlovian conditioning procedure that can be used to study the neural basis of reflex modification in an appetitive task. This opens up the possibility of assessing within a species whether a common neural solution has evolved to encode regularities in event relationships processed by different sensory systems. For example, it will be of interest to examine whether the principles and mechanisms of neural coding that underlie Pavlovian conditioning of the gill and siphon withdrawal reflex in Aplysia (Hawkins, Abrams, Carew, \& Kandel, 1983; Hawkins, Clark, \& Kandel, 1986; Ocurr, Walters, \& Byrne, 1985; Walters \& Byrne, 1983) also underlie Pavlovian conditioning of the biting response. Furthermore, it will be intriguing to explore how encoding of an emergent sensory property, such as roughness, impacts on strict activity-dependent models of conditioning.

\section{REFERENCES}

AnNAU, Z., \& KAMIN, L. J. (1961). The conditioned emotional response as a function of intensity of the US. Journal of Comparative \& Physiological Psychology, 54, 428-432.
Baux, G., Fossier, P., Trudeau, L.-E., \& Tauc, L. (1993). Transmitter release and calcium currents at an Aplysia buccal ganglion synapseII. Modulation by presynaptic receptors. Neuroscience, 53, 581-593.

Bitterman, M. E., Menzel, R., Fietz, A., \& Schafer, S. (1983). Classical conditioning of proboscis extension in honeybees (Apis mellifera). Journal of Comparative Psychology, 97, 107-119.

BLOCK, R. A., \& MCCONNELL, J. V. (1967). Classically conditioned discrimination in the planarian, Dugesia dorotocephala. Nature, 215 , 1465-1466.

Brown, P. L., \& JENKINS, H. M. (1968). Auto-shaping of the pigeon's key peck. Journal of the Experimental Analysis of Behavior, 11, 1-8.

Carew, T. J., Hawkins, R. D., \& Kandel, E. R. (1983). Differential classical conditioning of a defensive withdrawal reflex in Aplysia californica. Science, 219, 397-400.

Carew, T. J., Walters, E. T., \& Kandel, E. R. (1981). Classical conditioning in a simple withdrawal reflex in Aplysia californica. Journal of Neuroscience, 1, 1426-1437.

Cohen, J. L., Weiss, K. R., \& Kupfermann, I. (1978). Motor control of buccal muscles in Aplysia. Journal of Neurophysiology, 41, 157-180.

Colwill, R. M. (1996). Detecting associations in Pavlovian conditioning and instrumental learning in vertebrates and in invertebrates. In C. F. Moss \& S. J. Shettleworth (Eds.), Neuroethological studies of cognitive and perceptual processes (pp. 31-62). Boulder, CO: Westview Press.

Colwill, R. M., Absher, R. A., \& Roberts, M. L. (1988). Context-US learning in Aplysia californica. Journal of Neuroscience, 8, 44344439.

Colwill, R. M., \& Motzkin, D. K. (1994). Encoding of the unconditioned stimulus in Pavlovian conditioning. Animal Learning \& Behavior, 22, 384-394.

Cropper, E. C., Kupfermann, I., \& Weiss, K. R. (1990). Differential firing patterns of the peptide-containing cholinergic motor neurons B15 and B16 during feeding behavior in Aplysia. Brain Research, 522, 176-179.

Cropper, E. C., Miller, M. W., Vilim, F. S., Tenenbaum, R., KupferMANN, I., \& WEIss, K. R. (1990). Buccalin is present in the cholinergic motor neuron $\mathrm{B} 16$ of Aplysia and it depresses accessory radula closer muscle contractions evoked by stimulation of $\mathrm{B} 16$. Brain Research, 512, 175-179.

Cropper, E. C., Tenenbaum, R., Kolks, M. A. G., Kupfermann, I., \& WEISs, K. R. (1987). Myomodulin: A bioactive neuropeptide present in an identified cholinergic buccal motor neuron of Aplysia. Proceedings of the National Academy of Sciences, 84, 5483-5486.

DeCola, J. P., \& FANSELOW, M. S. (1995). Differential inflation with short and long CS-US intervals: Evidence of a nonassociative process in long-delay taste avoidance. Animal Learning \& Behavior, 23, 154-163.

Farley, J., \& AlkoN, D. L. (1985). Cellular mechanisms of learning, memory, and information storage. Annual Review of Psychology, 36, 419-494.

Farley, J., Grover, L. M., Sun, L., Huang, S. S., Eisthen, H. L., Girolami, C., \& WU, R. (1990). Chemosensory conditioning of Hermissenda crassicornis. Behavioral Neuroscience, 104, 583-596.

FIORE, L., \& MEUNIER, J.-M. (1979). Synaptic connections and functional organization in Aplysia buccal ganglia. Journal of Neurobiology, 10, 13-29.

FukUSHI, T. (1979). Properties of olfactory conditioning in the housefly, Musca domestica. Journal of Insect Physiology, 25, 155-159.

GAFFAN, E. A.. \& HART, M. M. (1981). Pigeons' withdrawal from an appetitive conditioned inhibitor under two training procedures. Quarterly Journal of Experimental Psychology, 33B, 77-94.

GormEzano, I. (1966). Classical conditioning. In J. B. Sidowski (Ed.), Experimental methods and instrumentation in psychology (pp. 385420). New York: McGraw-Hill.

GoRmEZANO, I. (1972). Investigations of defense and reward conditioning in the rabbit. In A. H. Black \& W. F. Prokasy (Eds.), Classical conditioning II: Current research and theory (pp. 151-181). New York: Appleton-Century-Crofts.

Gould, T. J., \& SteinmetZ, J. E. (1994). Multiple-unit activity from rabbit cerebellar cortex and interpositus nucleus during classical discrimination/reversal eyelid conditioning. Brain Research, 652, 98-106.

HAMmOND, L. J. (1967). A traditional demonstration of the properties 
of Pavlovian inhibition using differential CER. Psychonomic Science, 9, 65-66.

Hawkins, R. D., Abrams, T. W., Carew, T. J, \& Kandel, E. R. (1983). A cellular mechanism of classical conditioning in Aplysia: Activitydependent amplification of presynaptic facilitation. Science, 219, 400-405.

Hawkins, R. D., Carew, T. J., \& Kandel, E. R. (1986). Effects of interstimulus interval and contingency on classical conditioning of the Aplysia siphon withdrawal reflex. Journal of Neuroscience, 6, 16951701.

Hawkins, R. D., Clark, G., \& Kandel, E. R. (1986). Cell biological studies of learning in simple vertebrate and invertebrate systems. In Handbook of physiology: Sec 1. The nervous system: Vol. 6. Higher functions of the brain (pp. 25-83). Bethesda, MD: American Physiology Society.

Hawkins, R. D., Lalevic, N., Clark, G. A., \& Kandel, E. R. (1989) Classical conditioning of the Aplysia siphon-withdrawal reflex exhibits response specificity. Proceedings of the National Academy of Sciences, 86, 7620-7624.

Hearst, E., \& Franklin, S. R. (1977). Positive and negative relations between a signal and food: Approach-withdrawal behavior to the signal. Journal of Experimental Psychology: Animal Behavior Processes, 3, 37-52

Henderson, T. B., \& Strong, P. N., JR. (1972). Classical conditioning in the leech Macrobdella ditetra as a function of CS and UCS intensity. Conditional Reflex, 7, 210-215.

Hoffman, J. W., \& Fitzgerald, R. D. (1982). Bidirectional heart rate response in rats associated with excitatory and inhibitory stimuli. $A n-$ imal Learning \& Behavior, 10, 77-82.

Holland, P. C. (1990). Event representation in Pavlovian conditioning: Image and action. Cognition, 37, 105-131.

Jahan-Pawar, B., \& Fredman, S. M. (1983). Control of extrinsic feeding muscles in Aplysia. Journal of Neurophysiology, 49, 1481-1503.

JENKINS, H. M., \& MOORE, B. R. (1973). The form of the autoshaped response with food or water reinforcers. Journal of the Experimental Analysis of Behavior, 20, 163-181.

KANDEL, E. R. (1979). Behavioral biology of Aplysia: A contribution to the comparative study of opisthobranch molluscs. San Francisco: W. H. Freeman.

KaRRER, T., \& Sahley, C. L. (1988). Discriminative conditioning alters food preferences in the leech, Haemopis marmorata. Behavioral \& Neural Biology, 50, 311-324.

KupFermanN, I. (1974). Feeding behavior in Aplysia: A simpie system for the study of motivation. Behavioral Biology, 10, 1-26.

LEONARD, J. L., \& LUKOWIAK, K. (1986). The behavior of Aplysia californica cooper (Gastropoda; Opisthobranchia): I. Ethogram. Behaviour, 98, 320-360.

LICKEY, M. E. (1968). Learned behavior in Aplysia vaccaria. Journal of Comparative \& Physiological Psychology, 66, 712-718.

LICKEY, M. E., \& BERRY, R. W. (1966). Learned behavioral discrimination of food objects by Aplysia californica. Physiologist, 9, 230 .

Lloyd, P. E., Frankfurt, M., Stevens, P., Kupfermann, I., \& Weiss, K. R. (1987). Biochemical and immunocytological localization of the neuropeptides FMRFamide, SCPA, SCPB, to neurons involved in the regulation of feeding in Aplysia. Journal of Neuroscience, 7, 1123 1132

Lloyd, P. E., Mahon, A. C., Kupfermann, I., Cohen, J. L., Scheller, R. S., \& WEISS, K. R. (1985). Biochemical and immunocytological localization of molluscan small cardioactive peptides in the nervous system of Aplysia californica. Journal of Neuroscience, 5, 1851-1861.

MaCKINTOSH, N. J. (1974). The psychology of animal learning. London: Academic Press.

MaCkintosh, N. J. (1983). Conditioning and associative learning. Oxford: Oxford University Press.

Mitchell, D., Kirschbaum, E. H., \& Perry, R. L. (1975). Effects of neophobia and habituation on the poison-induced avoidance of exteroceptive stimuli in the rat. Journal of Experimental Psychology: Animal Behavior Processes, 1, 47-55.

Mitchell, D., Parker, L. F., \& Johnson, R. (1976). Absence of a gen- eralization decrement in the poison-induced avoidance of interoceptive stimuli in the rat. Physiological Psychology, 4, 121-123.

Mrtchell, D., Scott, D. W., \& Mitchell, L. K. (1977). Attenuated and enhanced neophobia in the taste-aversion "delay of reinforcement" effect. Animal Learning \& Behavior, 5, 99-102.

MOORE, J. W. (1972). Stimulus control: Studies of auditory generalization in rabbits. In A. H. Black \& W. F. Prokasy (Eds.), Classical conditioning II: Current research and theory (pp. 206-230). New York: Appleton-Century-Crofts.

Mpitsos, G. J., \& Cohan, C. S. (1986). Differential Pavlovian conditioning in the mollusc Pleurobranchaea. Journal of Neurobiology, $17,487-497$.

NeLson, M. C. (1971). Classical conditioning in the blowfly (Phormia regina): Associative and excitatory factors. Journal of Comparative \& Physiological Psychology, 77, 353-368.

OCURR, K. A., WALTERS, E. T., \& BYrNe, J. H. (1985). Associative conditioning analog selectively increases cAMP levels of tail sensory neurons in Aplysia. Proceedings of the National Academy of Sciences, 82, 2548-2552.

PavLov, I. P. (1927). Conditioned reflexes (G. V. Anrep, Trans.). London: Oxford University Press.

Pavlov, I. P. (1928). Lectures on conditioned reflexes (W. H. Grant, Trans.). New York: International Publishers.

PeARCE, J. M., \& RedheAd, E. S. (1993). The influence of an irrelevant stimulus on two discriminations. Journal of Experimental Psychology: Animal Behavior Processes, 19, 180-190.

Pfautz, P. L., Donegan, N. H., \& Wagner, A. R. (1978). Sensory preconditioning versus protection from habituation. Journal of Experimental Psychology: Animal Behavior Processes, 4, 286-295.

RESCORLA, R. A. (1967). Pavlovian conditioning and its proper control procedures. Psychological Review, 74, 71-80.

Rescorla, R. A. (1980). Pavlovian second-order conditioning: Studies in associative learning. Hillsdale, $\mathrm{NJ}$ : Erlbaum.

Rescorla, R. A. (1984). Comments on three Pavlovian paradigms. In D. L. Alkon \& J. Farley (Eds.), Primary neural substrates of learning and behavioral change (pp. 25-45). Cambridge: Cambridge University Press.

Rescorla, R. A., \& Holland, P. C. (1976). Some behavioral approaches to the study of learning. In M. R. Rosenzweig \& E. L. Bennett (Eds.), Neural mechanisms of learning and memory (pp. 165192). Cambridge, MA: MIT Press.

RiCKER, J. P., BRzORAD, J. N., \& HiRSCH, J. (1986). A demonstration of discriminative conditioning in the blow fly, Phormia regina. Bulletin of the Psychonomic Society, 24, 240-243.

Rosen, S. C., Miller, M. W., Weiss, K. R., \& Kupfermann, I. (1988). Activity of CB1-2 of Aplysia elicits biting-like responses. Society for Neuroscience Abstracts, 14, 608 .

Sahley, C. L., Gelperin, A., \& Rudy, J. W. (1981). One-trial associative learning modifies food odor preferences of a terrestrial mollusc. Proceedings of the National Academy of Sciences, 78, 640-642.

SCHNEIDERMAN, N. (1972). Response system divergences in aversive classical conditioning. In A. H. Black \& W. F. Prokasy (Eds.), Classical conditioning II: Current research and theory (pp. 341-376). New York: Appleton-Century-Crofts.

Schneiderman, N., Fuentes, I., \& Gormezano, I. (1962). Acquisition and extinction of the classically conditioned eyelid response in the albino rabbit. Science, 136, 650-652.

SMITH, M. (1968). CS-US interval and US intensity in classical conditioning of the rabbit's nictitating membrane response. Journal of Comparative \& Physiological Psychology, 66, 679-687.

Sossin, W. S., Kirk, M. D., \& Scheller, R. H. (1987). Peptidergic modulation of neuronal circuitry controlling feeding in Aplysia. Journal of Neuroscience, 7, 671-681.

SUssweIN, A. J., \& BYRNE, J. (1988). Identification and characterization of neurons initiating patterned neural activity in the buccal ganglia of Aplysia. Journal of Neuroscience, 8, 2049-2061.

Susswein, A. J., \& SChWARZ, M. (1983). A learned change of response to inedible food in Aplysia. Behavioral \& Neural Biology, 39, 1-6.

Susswein, A. J., Schwarz, M., \& Feldman, E. (1986). Learned 
changes of feeding behavior in Aplysia in response to edible and inedible foods. Journal of Neuroscience, 6, 1513-1527.

Teyke, T., Weiss, K. R., \& Kupfermann, I. (1990a). Appetitive feeding behavior of Aplysia: Behavioral and neural analysis of directed head turning. Journal of Neuroscience, 10, 3922-3934.

Teyke, T., Weiss, K. R., \& Kupfermann, I. (1990b). An identified neuron (CPR) evokes neuronal responses reflecting food arousal in Aplysia. Science, 247, 85-87.

Wagner, A. R., Stegel, S., Thomas, E., \& Ellison, G. D. (1964). Reinforcement history and the extinction of a conditioned salivary response. Journal of Comparative \& Physiological Psychology, 58, 354-358.

WALTERS, E. T. (1989). Transformation of siphon responses during conditioning of aplysia suggests a model of primitive stimulus-response association. Proceedings of the National Academy of Sciences, 86, 7616-7619.

WALTERS, E. T., \& BYrNE, J. H. (1983). Associative conditioning of single sensory neurons suggests a cellular mechanism for learning. Science, 219, 405-408.
Walters, E. T., Carew, T. J., \& Kandel, E. R. (1979). Classical conditioning in Aplysia californica. Proceedings of the National Academy of Sciences, 76, 6675-6679.

Walters, E. T., Carew, T. J., \& Kandel, E. R. (1981). Associative learning in Aplysia: Evidence for conditioned fear in an invertebrate. Science, 211, 504-506.

Wasserman, E. A., Franklin, S. R., \& Hearst, E. (1974). Pavlovian appetitive contingencies and approach versus withdrawal to conditioned stimuli in pigeons. Journal of Comparative \& Physiological Psychology, 86, 616-627.

Weiss, K. R., Cohen, J., \& Kupfermann, I. (1978). Modulatory control of buccal musculature by a serotonergic neuron (metacerebral cell) in Aplysia. Journal of Neurophysiology, 41, 181-203.

(Manuscript received October 25, 1995; revision accepted for publication October 18, 1996.) 